\title{
Changes occur from mixing chemical compounds: electrovalent bonds and covalent bonds
}

\author{
Ishan Kaseer Aman \\ Department of Chemistry, Faculty of Science, University of Colombo, Sri Lanka
}

\begin{abstract}
This article aims to distinguish compounds that have electrovalent and covalent bonds and distinguish between complex and non-complex formation reactions. This method by observing through the materials used in this experiment are $\mathrm{NaCl}, \mathrm{AgNO} 3, \mathrm{CHCl} 3, \mathrm{KCNS}$, $\mathrm{CH} 3 \mathrm{COOH}, \mathrm{CCl} 4, \mathrm{C} 2 \mathrm{H} 5 \mathrm{OH}, \mathrm{K} 3 \mathrm{Fe}(\mathrm{CN}) 6, \mathrm{HCl}$, methyl orange $(\mathrm{MO}), \mathrm{BaCl} 2, \mathrm{~K} 4 \mathrm{Fe}(\mathrm{CN}) 6$, $\mathrm{CuSO} 4, \mathrm{NH} 4 \mathrm{OH}$, and $\mathrm{FeCl} 3$. The results of the observations found a difference between complex and non-complex compounds. When mixed with KCNS, they can react which is indicated by a change in color, while non-complex compounds cannot react. The equation between ethanol solution and $\mathrm{CHCl} 3$, if each solution is added $\mathrm{AgNO} 3$ will produce a covalent compound, but the change is different where ethanol is added to AgNO3 to become cloudy white, while $\mathrm{CHCl} 3$ does not react.
\end{abstract}

Keywords: Chemical Compounds, Electrovalent, Covalent

Received : August 17, 2020

Received in Revised: August 25, 2020

Accepted: August 28, 2020

\section{Introduction}

In everyday life, we often find chemical reactions in the world around them and the changes that occur in them without question. For example, how does combustion occur, why gasoline burns and water does not, and other questions.

Chemical bonds also occur in the body. Almost all ionic compounds dissolve easily in water. The human body must maintain a number of ions to function properly, these ions are called electrolytes. Without the proper concentration of these electrolytes, nerve motion cannot transmit to the brain. When we sweat, we lose fluid in the form of electrolytes in the body which results in reduced or imbalanced electrolyte fluid in the body (Metheny, 2011).

Therefore, chemical bonding experiments were carried out by observing the changes that occur due to mixing of the existing compounds. In this case, this is done in order to understand common occurrences in nature related to chemical bonds, namely ionic and covalent bonds in order to understand the difference and understand how complex and not complex are formed. This article aims to distinguish compounds that have electrovalent and covalent bonds and distinguish between complex and non-complex formation reactions.

The principle of this experiment is to observe directly the changes that occur in the compounds that are treated in carrying out ionic bonds and covalent bonds and the formation of complex rather than complex reactions.

\section{Literature Review}

Chemical bonding is a topic that generally seems abstract because most of the concepts of chemical bonding are abstract, one cannot easily understand atoms or the interactions between atoms or other elementary particles. Chemical bond theory is thus a cognitive key needed to be able to visualize the world of microscopic chemistry Ültay, N. (2015). 
More than a century before the theory of quantum mechanics was presented, scientists had first thought about the properties of an element (under ambient conditions), in particular about how exactly different compounds are built from the constituent elements or atoms. The oldest concept needed to understand the intuitive thinking behind this is chemical bonding (Mingos, 2016).

When two or more atoms are close to each other, the electrons interact and form a new arrangement of electrons around the nucleus which has a lower total potential energy than the isolated atom. This reduction in energy stabilizes the arrangement relative to the isolated atoms by forming chemical bonds.

Chemical bonds are formed through the sharing of electrons or the transfer of electrons between atoms. This process leads to two ideal concepts regarding the chemical bond model (Cremer \& Kraka, 1984). When electrons are shared between atoms, the bond between them is called a covalent bond. When electrons move from one atom to another, the resulting bond is called an ionic bond. Although many real-life examples of these two extreme ideal models are known, most actual bonds are neither truly ionic nor completely covalent. Real molecules show a continuum from pure ionic bonds to pure covalent bonds, and most of them have mixed ionic and covalent properties. The bonds that occur due to partial charge transfer are polar covalent (Oliveira et al., 2016).

\section{Ionic Bonds}

Ionic compounds occur because the constituent particles are positively and negatively charged and interact with ionic bonds. These compounds are usually produced by interactions between metals and non-metals. The release and acceptance of electrons tends to lead to an electron configuration similar to that of the noble gases. This tendency is apparently controlled by changes in potential energy. It produces a stable ionic compound when the potential energy decreases during the formation process or is exothermic. Or on the whole, the energy required for endodermic processes must be less than the energy released by exothermic processes (Steinfeld, 1998).

Metals form cations because the data release electrons relatively easily, which is indicated by the low ionization energy of the metal. For the main elemental metals, the electron loss tends to be at the outermost level to vacate. Then removing the next electron, the electron that is at the inner level, is very difficult because it requires a large amount of energy. For non-metallic elements, the addition of electrons to atoms is an exothermic process so that the formation of anions is preferred by non-metallic elements (Moore, 2013).

Ions tend to have a noble gas configuration because to remove electrons from orbitals at the outermost level no longer requires too much energy while releasing electrons so as to destroy the same configuration as noble gases requires a fairly high energy and is not proportional to the increase in energy due to the increase in charge. For non-metallic elements, the addition of electrons in the outer energy level can be exothermic or endothermic. However, after the outermost level is completely filled (the electron configuration is the same as one of the noble gases), the addition of the next electron will be placed at a level with a greater value of $n$ so that it takes place endothermically. The energy required is not proportional to the increase in energy due to the increase in charge. Thus, when viewed energetically by both metals and non-metals, a state with the same electron configuration as the noble gas is preferred. While it is possible to distinguish specifically between ionic bonds and other types of bonds, some arbitrary decisions such as the extent to which the excited ion state should be considered should be avoided (Pauling, 1932). 
If the only factors affecting the formation of ionic compounds are ionization energy and electron affinity, only a few ionic compounds will be formed. In nearly all ionic compounds, the energy required to remove electrons from the metal is greater than the energy freed up to form ions from neutral atoms in ionic compounds is almost always endothermic. The more so if the anion formation has a charge of -2 or greater.

The main reason that ion is stable is because of the attraction of oppositely charged antarions. When an ionic compound is formed, the attraction between the antarions produces a large enough energy, and a decrease in potential energy occurs. The amount of energy depends on the ionic ring and the charge. The smaller the ionic radius and the greater the ionic charge, the greater the energy of the attraction generated.

\section{Covalent Bonds}

Covalent bonds are formed when there are not enough electrons available for each atom to reach the complete octet. Each atom can complete its octet by sharing electrons in covalent bonds. The requirement for the hydrogen atom is that the electron configuration of helium is achieved, that is, it is surrounded by two electrons.

The octet rule applies to the elements in the second period of the periodic table. These elements only have the prbital in the $2 \mathrm{~s}$ and $2 \mathrm{p}$ subshells which hold a maximum of eight electrons.

\section{Complex Compounds}

A complex will be formed between a cation or metal with several neutral molecules or electron donor ions. The cation or metal functions as a central ion while the neutral molecule or electron donor ion functions as a surrounding group or often called a ligand. The coordination covalent bonds in these complex compounds occur due to donations of electron pairs from the ligands into the empty orbitals of the central ion. In general, the central ion has d orbitals that are not fully filled with electrons so that it can function as an acceptor for the electron pair. In general, the central ion has $d$ orbitals which are not completely filled with electrons so that it can function as an acceptor for the electron pair. This characteristic causes several distinctive properties, including unique color, the formation of paramagnetic compounds, catalytic activity, and especially the tendency to form complex compounds (Yatsimirskii, 2012).

\section{Methods}

The materials used in this experiment were $\mathrm{NaCl}, \mathrm{AgNO} 3, \mathrm{CHCl} 3, \mathrm{KCNS}, \mathrm{CH} 3 \mathrm{COOH}$, $\mathrm{CCl} 4, \mathrm{C} 2 \mathrm{H} 5 \mathrm{OH}, \mathrm{K} 3 \mathrm{Fe}(\mathrm{CN}) 6, \mathrm{HCl}$, methyl orange (MO), $\mathrm{BaCl} 2, \mathrm{~K} 4 \mathrm{Fe}(\mathrm{CN}) 6, \mathrm{CuSO} 4$, $\mathrm{NH} 4 \mathrm{OH}$, and $\mathrm{FeCl} 3$.

The tools used in this experiment are test tubes and scale pipettes. For the precipitation of Nitrate Salt (AgNO3) 3 test tubes were prepared, each test tube filled with $1 \mathrm{~mL}$ of AgNO3. The first test tube was dripped with 3-5 drops of $\mathrm{NaCl}$, the second test tube was dropped by 3-5 drops of $\mathrm{CCl} 4$, the third test tube was dropped by 3-5 drops of $\mathrm{CHCl} 3$. Pay attention and note the changes that occur. For the reaction with the Methyl Orange (MO) indicator, 3 test tubes were prepared, the first test tube was filled with $2.5 \mathrm{~mL}$ of $\mathrm{HCl}$, the second test tube was filled with $2.5 \mathrm{~mL}$ of $\mathrm{CH} 3 \mathrm{COOH}$, the third test tube was filled with $\mathrm{C} 2 \mathrm{H} 5 \mathrm{OH}$, as much as 2, $5 \mathrm{~mL}$. Each tube was dripped with 2-3 drops of the methyl orange (MO) indicator. Then observe and record the changes that occur.

Reaction with Ammonium Hydroxide, Prepared 2 test tubes, each tube filled with $1 \mathrm{~mL}$ $\mathrm{CuSO} 4$. Each tube is dripped with a few drops of ammonium hydroxide solution, then added excessively until there is no sedimentation, the first test tube is added with 2-3 drops of 
$\mathrm{BaCl} 2$ solution, the second test tube is added with 2-3 drops of $\mathrm{K} 4 \mathrm{Fe}(\mathrm{CN}) 6$. Be noticed and note the changes that occur.

For the reaction without Ammonium Hydroxide, 2 test tubes were prepared, each tube was filled with $1 \mathrm{~mL} \mathrm{CuSO} 4$, the first test tube was added with $\mathrm{BaCl} 2$ solution of 2-3 drops, the second test tube was added with $\mathrm{K} 4 \mathrm{Fe}(\mathrm{CN}) 6$ as much as 2-3 drops. Pay attention and note the changes that occur.

The reaction with potassium thiocyanate (KCNS) prepared 2 test tubes. The first test tube is filled with $1 \mathrm{~mL}$ of $\mathrm{FeCl} 3$, the second test tube is filled with $1 \mathrm{~mL}$ of $\mathrm{K} 3 \mathrm{Fe}(\mathrm{CN}) 6$. Each test tube was added 2-3 drops of KCNS. Be noticed and note the changes that occur.

\section{Results and Discussion}

Table 1. Precipitation of Nitrate Salt

\begin{tabular}{|c|c|c|}
\hline Solvent & + AgNO $_{3}$ & Description \\
\hline $\mathrm{NaCl}$ & White sediment & Ionic Bonds \\
$\mathrm{CCl}_{4}$ & Cloudy & Covalent Bonds \\
$\mathrm{CHCl}_{3}$ & Do not change & Covalent Bonds \\
\hline
\end{tabular}

Table 2. Reaction With Methyl Orange (M.O) Indicator

\begin{tabular}{|c|c|c|}
\hline Solvent & +MO & Description \\
\hline $\mathrm{HCl}$ & Deep Red & Strong acid \\
$\mathrm{CH}_{3} \mathrm{COOH}$ & Red & Weak acids \\
$\mathrm{CH}_{3} \mathrm{CH}_{2} \mathrm{OH}$ & Orange & Weak acids \\
\hline
\end{tabular}

Table 3. Precipitation of Hydroxide Salts

\begin{tabular}{|c|c|c|c|}
\hline \multirow{2}{*}{ Solvent } & \multicolumn{2}{|c|}{ Reactor } & \multirow{2}{*}{ Description } \\
\cline { 2 - 3 } & $\mathbf{B a C l}_{\mathbf{2}}$ & $\mathbf{K}_{\mathbf{4}} \mathbf{F e}(\mathbf{C N})_{\mathbf{6}}$ & \\
\hline $\mathrm{CuSO}_{4}+\mathrm{NH}_{4} \mathrm{OH}$ & Blue there is & Chocolate has & Complex \\
a little & sediment & sediment & Compounds \\
$\mathrm{CuSO}_{4}+\mathrm{NH}_{4} \mathrm{OH}$ & Blue there is & Blue solution & Complex \\
Excess $^{\text {CuSO }}$ & sediment & & Compounds \\
& Chocolate has & White sediment & Complex \\
& sediment & & Compounds \\
\hline
\end{tabular}

Tabel 4.4 Pengendapan KCNS

\begin{tabular}{|c|c|c|}
\hline Solvent & + KCNS & Description \\
\hline $\mathrm{FeCl}_{3}$ & Yellow turns blood red & Complex Compounds \\
$\mathrm{K}_{3} \mathrm{Fe}(\mathrm{CN})_{6}$ & Didn't react & Not a complex compound \\
\hline
\end{tabular}

\section{Reaction}

The reaction of adding sulfuric salts
a. $\mathrm{NaCl}$
$+\mathrm{AgNO}_{3}$
$\longrightarrow \quad \mathrm{AgCl}+\mathrm{NaNO}_{3}$
b. $\mathrm{CCl}_{4}$
$+\mathrm{AgNO}_{3}$
c. $\mathrm{CHCl}_{3}$
$+\quad \mathrm{AgNO}_{3}$

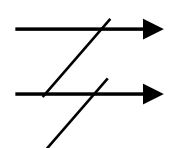
No React
No React

\section{Reaction of Hydroxide Salt Precipitation}

\section{Ditambahkan Amonia}




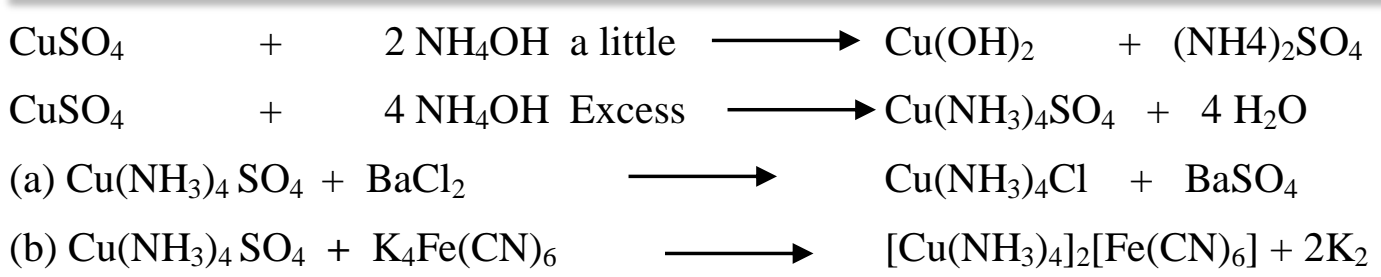

Without Addition of Ammonia

$\begin{array}{ll}\mathrm{CuSO}_{4} & +\mathrm{BaCl}_{2} \\ \mathrm{CuSO}_{4} & +\mathrm{K}_{4} \mathrm{Fe}(\mathrm{CN})_{6}\end{array}$

\section{Reaction with KCNS}

\begin{tabular}{|c|c|c|c|c|}
\hline $\mathrm{FeCl}_{3}$ & + & $3 \mathrm{KCNS}$ & $\mathrm{Fe}(\mathrm{CNS})_{3}$ & $3 \mathrm{KCl}$ \\
\hline $\mathrm{K}_{4} \mathrm{Fe}(\mathrm{CN})_{6}$ & + & KCNS & No react & \\
\hline
\end{tabular}

Nitrate salt precipitation experiments aim to determine the ionic bond compounds or covalent bonds in a solution. In this practicum experiment, an experiment was carried out by adding AgNO3 which functions as a precipitate compound to form nitrate salts. $\mathrm{NaCl}$ is added with AgNO3 to form a white precipitate which shows a sign that it is an ionic bond, ethanol is added with $\mathrm{AgNO} 3$ to form a dirty white precipitate which is a covalent bond and $\mathrm{CHCl} 3$ is added with AgNO3, there is no reaction which is a covalent bond. To determine ionic and covalent bonds, this experiment can be used to find out how to react with the nitrate salt.

The reaction experiment with the methyl orange indicator, $\mathrm{HCl}$ dropping $\mathrm{MO}$ solution will be solid red which indicates that it is a strong acid, while $\mathrm{CH} 3 \mathrm{COOH}$ is dripped with $\mathrm{MO}$ the solution will be red which shows that it is a weak acid and $\mathrm{CH} 3 \mathrm{CH} 2 \mathrm{OH}$ is dropped with $\mathrm{MO}$ the solution will be orange which indicates weak acids.

In the hydroxide salt deposition experiment, $\mathrm{CuSO} 4$ solution was added with $\mathrm{NH} 4 \mathrm{OH}$ and a little dripped with $\mathrm{BaCl} 2$ a blue precipitate would occur when drops with $\mathrm{K} 4 \mathrm{Fe}(\mathrm{CN}) 6$ would occur a brown precipitate. When $\mathrm{CuSO} 4$ is added, excess $\mathrm{NH} 4 \mathrm{OH}$ drops with $\mathrm{BaCl} 2$ it will turn blue and there is a white precipitate and when you drop it with $\mathrm{K} 4 \mathrm{Fe}(\mathrm{CN}) 6$ there will be a brown precipitate. When $\mathrm{CuSO} 4$ is added with $\mathrm{BaCl} 2$, a brown precipitate will occur, and if it is dripped with $\mathrm{K} 4 \mathrm{Fe}(\mathrm{CN}) 6$ it will become a blue solution and a white precipitate. These three compounds form ionic bonds which are complex compounds.

Reaction experiments with $\mathrm{KCNS}, \mathrm{FeCl} 3$, and $\mathrm{K} 3 \mathrm{Fe}(\mathrm{CN}) 6$ which will be tested by adding $\mathrm{KSCN}$ in each sample. When $\mathrm{FeCl} 3$ is reacted with $\mathrm{KSCN}$, the $\mathrm{FeCl} 3$ solution will change from yellow to blood red, indicating that it is complex. And if $\mathrm{K} 3 \mathrm{Fe}(\mathrm{CN}) 6$ is reacted with $\mathrm{KSCN}, \mathrm{K} 3 \mathrm{Fe}(\mathrm{CN}) 6$ solution does not react which makes it not a complex compound.

\section{Conclusion}

The results showed the difference between complex and non-complex compounds, complex compounds when mixed with KCNS can react which is indicated by a change in color, while non-complex compounds cannot react. The equation between ethanol solution and $\mathrm{CHCl} 3$, if each solution is added $\mathrm{AgNO} 3$ will produce a covalent compound, but the change is different where ethanol is added to $\mathrm{AgNO} 3$ to become cloudy white, while $\mathrm{CHCl} 3$ does not react. The suggestion for the laboratory is that the lighting in the laboratory should be made brighter so that the practice atmosphere is more supportive. Experiments must be carried out with a thorough and strong understanding of the results of the experiment. 


\section{References}

Oliveira, V., Kraka, E., \& Cremer, D. (2016). The intrinsic strength of the halogen bond: Electrostatic and covalent contributions described by coupled cluster theory. Physical Chemistry Chemical Physics, 18(48), 33031-33046.

Metheny, N. (2011). Fluid and electrolyte balance. Jones \& Bartlett Publishers.

Ültay, N. (2015). The Effect Of Concept Cartoons Embedded Within Context-Based Chemistry: Chemical Bonding. Journal of Baltic Science Education, 14(1).

Mingos, D. M. P. (2016). The Chemical Bond II. Springer International: Cham, Switzerland.

Cremer, D., \& Kraka, E. (1984). A description of the chemical bond in terms of local properties of electron density and energy. Croatica Chemica Acta, 57(6), 1259-1281.

Steinfeld, A., Kuhn, P., Reller, A., Palumbo, R., Murray, J., \& Tamaura, Y. (1998). Solarprocessed metals as clean energy carriers and water-splitters. International Journal of Hydrogen Energy, 23(9), 767-774.

Moore, J. J. (2013). Chemical metallurgy. Elsevier.

Pauling, L. (1932). The nature of the chemical bond. IV. The energy of single bonds and the relative electronegativity of atoms. Journal of the American Chemical Society, 54(9), 3570-3582. 